\title{
Solubility of $p$-xylene in methane and ethane and implications for freeze-out at LNG conditions
}

\author{
Arman Siahvashi ${ }^{1}$, Saif ZS. Al Ghafri ${ }^{1}$, Thomas J. Hughes ${ }^{2}$, Brendan F. Graham ${ }^{1}$, Stanley H. \\ Huang $^{3}$ and Eric F. May ${ }^{1}$ * \\ ${ }^{1}$ Fluid Science and Resources Division, Department of Chemical Engineering, University of \\ Western Australia, Crawley, Western Australia 6009, Australia \\ ${ }^{2}$ Oil and Gas Engineering, Resources Engineering Program, Department of Civil \\ Engineering, Monash University, Clayton, Victoria 3800, Australia \\ ${ }^{3}$ Chevron Energy Technology Company, Houston Texas 77002, United States \\ *Corresponding Author: Phone: +61-8-6488 2954, Fax: +61-8-6488 1024, \\ E-mail: eric.may@uwa.edu.au
}

\section{Abstract}

Even at trace concentrations the presence of heavy hydrocarbons such as BTEX compounds (benzene, toluene, ethylbenzene, and xylenes) in liquefied natural gas (LNG) production streams poses a significant risk of blockage and eventually plant shutdown. However, although $p$-xylene has the highest melting temperature of all the BTEX compounds, no data are available for its solubility in liquid methane or ethane. In this work, sapphire equilibrium cells housed in either an air bath or a cryogenic thermostat fitted with periscopes were used to measure melting (liquidus) temperatures for synthetically prepared methane $+p$-xylene and ethane $+p$-xylene mixtures at temperatures from $200 \mathrm{~K}$ and pressures up to $22.5 \mathrm{MPa}$. Peltier-driven copper posts, which could be sub-cooled relative to the bulk liquid mixture, controlled the location of the solid formed within each cell. For the methane $+p$-xylene system both VLE and SLVE data sets were measured and used separately to tune the binary interaction parameter (BIP) within the Peng Robinson equation of state. The VLE-tuned BIP systematically under-predicted the measured melting temperatures for this binary by up to $5.2 \mathrm{~K}$, while the SLVE-tuned BIP could represent the melting temperature data with an r.m.s. deviation of $0.4 \mathrm{~K}$. For ethane $+p$-xylene, a BIP estimated using a group contribution method systematically over-predicted the measured melting temperatures by as much as $14.6 \mathrm{~K}$. Tuning the ethane $+p$-xylene BIP to the measured SLE data more than halved the model's r.m.s. deviation to $3.1 \mathrm{~K}$. The use of BIPs tuned to VLE data rather than SLVE data has significant implications for freeze-out risk assessments in LNG production. For example, at operating conditions typical of an LNG plant's main cryogenic heat exchanger, the solubility of $p$-xylene in liquid methane predicted using a BIP tuned to VLE data is 20 times larger than the solubility predicted using a BIP tuned to SLVE data.

Key Words: LNG; BTEX; p-xylene; methane; ethane; cryogenics 


\section{Introduction}

Avoiding heavy hydrocarbon (HHC) precipitation is an ongoing, ubiquitous challenge throughout the global oil and gas processing industry. Wax precipitation in pipelines and heavy hydrocarbon $\left(\mathrm{C}_{5^{+}}\right)$freeze-out in liquefied natural gas (LNG) production are among those challenges. In an LNG plant, natural gas from the gathering system must be treated to separate-out the hydrogen sulfide $\left(\mathrm{H}_{2} \mathrm{~S}\right)$, carbon dioxide $\left(\mathrm{CO}_{2}\right)$, water and then heavy hydrocarbons, each of which can solidify during liquefaction if present at sufficiently high concentrations. Separation of the heavy hydrocarbons, including the aromatics (benzene, toluene, ethylbenzene, xylene) collectively known as BTEX compounds, naphthenics (e.g. cyclo-hexane), and paraffins ( $n$-hexane and above), typically takes place in a distillation tower called a scrub column, which aims to remove virtually all components heavier than propane from the feed stream and direct them into the liquid (bottoms) product [1] . However, carry-over of these $\mathrm{C}_{5+}$ hydrocarbons into the vapour (overheads) product, even at trace concentrations, can result in freeze-out and consequently blockages in the main cryogenic heat exchanger. Such blockages can potentially become so severe that a shut down and warm-up of the plant is necessary, leading to a significant loss of production and revenue [2-4].

The pure component triple point temperatures of hydrocarbons which could potentially be present in sufficient quantities such that they are prone to freeze-out in LNG production are tabulated in Table 1, along with triple point pressures, enthalpies of fusion and molar volume changes on fusion at the triple point, and the Clausius-Clapeyron calculated change in melting temperature with pressure. It is evident that $p$-xylene $\left(\mathrm{C}_{8} \mathrm{H}_{10}\right)$, benzene $\left(\mathrm{C}_{6} \mathrm{H}_{6}\right)$ and neopentane $\left(\mathrm{C}_{5} \mathrm{H}_{12}\right)$ have the highest triple point and hence melting temperatures, suggesting these compounds might carry a high freeze-out risk. Although LNG is liquefied in the plant's main cryogenic heat exchanger at pressures typically between 4 and $6 \mathrm{MPa}$, the effect of pressure on the melting temperature of the solid is typically relatively small (less than $2 \mathrm{~K}$ increase from the triple point condition for all components in Table 1 except neopentane). More importantly, it is the paucity of experimental data for the solubility of such heavy hydrocarbons in LNG mixtures, or even in simple methane-rich binary systems that limits the accuracy of predictive engineering models used to avoid freeze-out problems [5-7]. 
Table 1. Triple point temperatures $\left(T_{\mathrm{t}}\right)$ of key pure heavy hydrocarbons (arranged from high to low), as well as triple point pressures $\left(p_{t}\right)$, enthalpies of fusion $\left(\Delta_{\text {fus }} H\right)$ and molar volume changes on fusion ( $\Delta_{\text {fus }} V$ ) at the triple point, and change in melting temperature as a function of pressure calculated from the Clausius-Clapeyron equation ${ }^{\mathrm{a}}\left(\mathrm{d} T_{\mathrm{m}} / \mathrm{d} p\right)$. This temperature, combined with their concentration in the natural gas to be liquefied, provides an initial indication of the extent of freeze-out risk in LNG production. Data from the Design Institute for Physical Properties (DIPPR) 801 Database [8] unless otherwise indicated.

\begin{tabular}{|c|c|c|c|c|c|c|}
\hline \multicolumn{2}{|c|}{ Heavy Hydrocarbon Solute } & \multirow[t]{2}{*}{$T_{t} / K$} & \multirow[t]{2}{*}{$p_{t} / P a$} & \multirow[t]{2}{*}{$\begin{array}{c}\Delta_{\mathrm{fus}} H / \\
\mathrm{kJ} \cdot \mathrm{mol}^{-1}\end{array}$} & \multirow[t]{2}{*}{$\begin{array}{c}\Delta_{\text {fus }} V / \\
\mathrm{ml} \cdot \mathbf{m o l}^{-1}\end{array}$} & \multirow[t]{2}{*}{$\begin{array}{l}\left(\mathrm{d} T_{\mathrm{m}} / \mathrm{dp}\right) / \\
\mathrm{K} \cdot \mathrm{MPa}^{-1}\end{array}$} \\
\hline Name & CAS No. & & & & & \\
\hline p-Xylene & $106-42-3$ & 286.41 & 575.5 & 17.11 & 18.58 & 0.31 \\
\hline Benzene & $71-43-2$ & 278.68 & 4764 & 9.866 & 10.40 & 0.29 \\
\hline Neopentane & $463-82-1$ & 256.6 & 35740 & 3.146 & 9.58 & 0.78 \\
\hline o-Xylene & $95-47-6$ & 247.98 & 21.84 & 13.6 & 11.70 & 0.21 \\
\hline$n$-Decane & $124-18-5$ & 243.51 & 1.393 & 28.71 & 26.67 & 0.23 \\
\hline m-Xylene & $108-38-3$ & 225.3 & 3.180 & 11.57 & $11.13^{\mathrm{b}}$ & 0.22 \\
\hline n-Nonane & $111-84-2$ & 219.66 & 0.431 & 15.47 & 20.71 & 0.29 \\
\hline n- Octane & $111-65-9$ & 216.38 & 2.108 & 20.74 & 18.58 & 0.19 \\
\hline n-Heptane & $142-82-5$ & 182.57 & 0.183 & 14.05 & 13.84 & 0.18 \\
\hline Ethylbenzene & $100-41-4$ & 178.2 & 0.004 & 9.180 & 11.86 & 0.23 \\
\hline Toluene & $108-88-3$ & 178.18 & 0.048 & 6.636 & $6.83^{\mathrm{c}}$ & 0.18 \\
\hline n-Hexane & $110-54-3$ & 177.83 & $1.36^{\mathrm{d}}$ & $13.08^{\mathrm{e}}$ & 12.59 & 0.17 \\
\hline
\end{tabular}

${ }^{a}$ Clausius-Clapeyron equation: $\mathrm{d} T_{\mathrm{m}} / \mathrm{d} p=T_{\mathrm{f}} \Delta_{\text {fus }} V / \Delta_{\text {fus }} H$.

${ }^{\mathrm{b}}$ calculated using density of solid $m$-xylene from Schinke and Sauerwald [9]

${ }^{\mathrm{c}}$ calculated using density of solid toluene estimated at the triple point temperature by extrapolation of crystallographic densities of Anderson et al. [10] at $T=165 \mathrm{~K}$ and Nayak et al. [11] at $T=150 \mathrm{~K}$.

d triple pressure of $n$-hexane from Carruth and Kobayashi [12]

e enthalpy of fusion of $n$-hexane from Douslin and Huffman [13]

The majority of HHC solubility data in the literature focus on binary systems as these help establish the fundamental interactions between pairs of species which are central to the modelling of multi-component LNG-like mixtures.

Table 2 shows a literature survey of the most LNG-relevant and commonly studied binary mixtures of heavy hydrocarbons in liquid methane and ethane. Benzene is often present in natural gas at relatively high concentrations (e.g. greater than 1000 parts-per-million) and is considered to have the most potent freeze-out risk of the heavy hydrocarbons during the liquefaction process. Benzene and $n$-hexane have been the focus of most research studying methane-rich binaries with 181 and 100 data points, respectively, while in ethane-rich binaries, benzene and cyclohexane are the solutes which have been studied the most, with 
approximately 70 data points combined. Somewhat surprisingly, no data have been published in the open literature for binary mixtures of $p$-xylene with either methane or ethane, even though as a pure substance $p$-xylene has the highest melting temperature among the heavy hydrocarbons listed in Table 1 . This suggests that the predictions of any thermodynamic model for the melting (liquidus) temperature of natural gas mixtures containing $p$-xylene are likely to be inaccurate. This motivates the need for reliable solubility measurements for the methane $+p$-xylene and ethane $+p$-xylene binaries.

Table 2. Literature survey on the melting (liquidus) temperature measurements of the most studied binary mixtures rich in either $\mathrm{C}_{1}$ or $\mathrm{C}_{2}$, and relevant to LNG production.

\begin{tabular}{|c|c|c|c|c|c|}
\hline Mixture & $\begin{array}{c}\text { Mole Fraction } \\
\text { Range }\end{array}$ & $\begin{array}{c}\text { Melting } \\
\text { Temperature } \\
\text { Range / K }\end{array}$ & $\begin{array}{l}\text { Total Data } \\
\text { Sets }\end{array}$ & $\begin{array}{l}\text { Total Data } \\
\text { Points }\end{array}$ & Reference \\
\hline Methane $+n$-Pentane & $0.0 \leq x_{\mathrm{C}_{1}} \leq 1.0$ & $90-143$ & 7 & 60 & [14-20] \\
\hline Methane + Cyclopentane & $0.98<\boldsymbol{x}_{\mathrm{C}_{1}}<0.99$ & $100-112$ & 1 & 2 & [14] \\
\hline Methane $+n$-Hexane & $0.0 \leq \boldsymbol{x}_{\mathrm{C}_{1}} \leq 1.0$ & $90-178$ & 7 & 100 & {$[15,20-25]$} \\
\hline Methane + Cyclohexane & $0.0 \leq \boldsymbol{x}_{\mathbf{C}_{1}}<1.0$ & $99-280$ & 2 & 48 & {$[22,24]$} \\
\hline Methane $+n$-Heptane & $0.0<\boldsymbol{x}_{\mathrm{C}_{1}}<1.0$ & $94-181$ & 5 & 62 & [24-28] \\
\hline Methane $+n$-Octane & $0.0 \leq \boldsymbol{x}_{\mathrm{C}_{1}} \leq 1.0$ & $90-217$ & 5 & 55 & $\begin{array}{c}{[20,22,29-} \\
31]\end{array}$ \\
\hline Methane $+n$-Nonane & $0.0 \leq \boldsymbol{x}_{\mathbf{C}_{1}}<1.0$ & $161-220$ & 2 & 13 & {$[20,26]$} \\
\hline Methane $+n$-Decane & $0.0 \leq \boldsymbol{x}_{\mathbf{C}_{1}}<0.5$ & $236-244$ & 1 & 14 & [32] \\
\hline Methane + Benzene & $0.0<\boldsymbol{x}_{\mathrm{C}_{1}} \leq 1.0$ & $90-278$ & 8 & 181 & $\begin{array}{c}{[24,25,31,} \\
33-37]\end{array}$ \\
\hline Methane + Toluene & $0.98<\boldsymbol{x}_{\mathrm{C}_{1}}<1.0$ & $92-173$ & 3 & 27 & {$[16,25,38]$} \\
\hline Ethane $+n$-Pentane & $0.85<x_{\mathrm{C}_{2}}<0.99$ & $90-114$ & 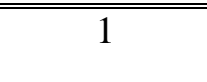 & 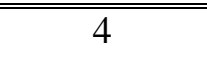 & [18] \\
\hline Ethane $+n$-Hexane & $0.99<\boldsymbol{x}_{\mathrm{C}_{2}}<1.0$ & $90-113$ & 1 & 3 & {$[18]$} \\
\hline Ethane + Cyclohexane & $0.0<\boldsymbol{x}_{\mathrm{C}_{2}}<0.94$ & $145-255$ & 1 & 23 & [39] \\
\hline Ethane $+n$-Heptane & $0.99<\boldsymbol{x}_{\mathrm{C}_{2}}<1.0$ & $112-113$ & 1 & 2 & [18] \\
\hline Ethane $+n$-Octane & $0.0<\boldsymbol{x}_{\mathrm{C}_{2}}<0.75$ & $150-210$ & 1 & 13 & {$[40]$} \\
\hline Ethane $+n$-Decane & $0.0<\boldsymbol{x}_{\mathrm{C}_{2}}<0.60$ & $165-235$ & 1 & 15 & {$[40]$} \\
\hline Ethane + Benzene & $0.0<\boldsymbol{x}_{\mathrm{C}_{2}}<1.0$ & $97-275$ & 2 & 40 & {$[36,39]$} \\
\hline
\end{tabular}


The main objectives of this work were to 1) demonstrate the development of an apparatus which consists of a cryogenic thermostat equipped with a pair of periscopes and a visual high pressure sapphire cell, and 2) extend the body of experimental data for the binary systems detailed in Table 2 by measuring melting temperatures in the previously un-studied binary mixtures of $p$-xylene (solute) in methane and in ethane (as solvent).

\section{Experimental}

In our previous work we reported the design, construction and validation of a specialized high pressure visual cell, which utilizes a Peltier-driven cold finger to allow accurate measurements of solid-liquid equilibrium (SLE) in different hydrocarbon mixtures via the synthetic method. [6] To measure the solubility of $p$-xylene in methane and ethane binary mixtures, we have employed this visual cell in two distinct thermal environments: 1) an incubation air bath as discussed by Siahvashi et al. [6], and 2) a multi-stage cryogenic thermostat, hereafter referred to as the CryoSolid apparatus. The CryoSolid apparatus is equipped with a pair of periscopes enabling the requisite visualization at low temperatures where normal cameras do not function.

\subsection{CryoSolid Apparatus}

The CryoSolid apparatus is shown schematically in Figure 1. The main elements include a high pressure sapphire cell, designed to operate at a maximum pressure of $31 \mathrm{MPa}$; a cryogenic thermostat equipped with periscopes, designed to operate at a minimum temperature of $90 \mathrm{~K}$; two high pressure syringe pumps; temperature and pressure monitoring and control systems; and a liquid nitrogen dosing system.

Figure 2 shows the core of the CryoSolid apparatus: the visual high-pressure equilibrium cell described previously [6] , so only a brief description is presented here. The cell utilised a high precision sapphire tube (Rayotek Scientific) with dimensions of $57.22 \mathrm{~mm}( \pm 0.02 \mathrm{~mm}) \mathrm{OD}$, $38.30 \mathrm{~mm}( \pm 0.02 \mathrm{~mm}) \mathrm{ID}$, and $74.7 \mathrm{~mm}( \pm 0.1 \mathrm{~mm})$ height. The sapphire tube was supported by Nitronic 50 high strength stainless steel base, top and four guide poles, and was sealed at each end by 25\% glass-filled trapezoidal Teflon O-rings. As part of this work, this sealing system was successfully tested at cryogenic conditions down to $90 \mathrm{~K}$ and up to $20 \mathrm{MPa}$ without any detectable leakage. The maximum cooling or heating rate applied to the CryoSolid apparatus was limited to $1 \mathrm{~K} \cdot \mathrm{min}^{-1}$ to minimise the risk of thermal shock or damage to the system, and especially to the sapphire tube. The available sample volume in 
the sapphire cell was calibrated in-situ using the syringe pumps and found to be approximately $55 \mathrm{~mL}$.

As shown in Figure 3, the equilibrium cell was housed in a cryogenic thermostat designed and constructed in-house at the University of Western Australia. It was similar in concept but larger than the cryogenic thermostats described by Rufford et al. [41] and by May et al. [1] for adsorption and VLE measurements, respectively, with blind equilibrium cells. The cryogenic thermostat used in this work was approximately 1.5-meter high and comprised of a stainless steel can, a radiation shield, a copper can concentrically arranged and surrounding the equilibrium cell. These were suspended from the lid of a Dewar, which was partially filled with liquid nitrogen. The lid also contained the ends of three periscopes to allow illumination and observation of the visual equilibrium cell. The periscopes were equipped at each end with 3-inch OD view flanges designed for a cryogenic environment (supplied by MDC Vacuum Products LLC). A $45^{\circ}$-angled mirror was fitted into the right angle join of the pipes comprising the periscope. Each periscope terminated in a second view window near the equilibrium cell. To avoid any internal condensation, the periscopes were filled with helium to around 0.15 MPa after evacuation. A light source was located at the ambient temperature end of one periscope to illuminate the cell, while a camera was located at the ambient temperature end of the second periscope to capture and record the image of the sapphire cell. These two periscopes were offset by $90^{\circ}$ from each other. A third periscope, offset by $180^{\circ}$ from the first one, was incorporated into the cryogenic thermostat as an additional view port allowing the other side of the copper tip to be seen. If required, it was also used to transmit additional light to enhance the image quality captured by the camera.

The stainless steel can and the copper can were sealed using a Mylar film and tested at temperatures down to around $100 \mathrm{~K}$ : to increase the thermal isolation of the copper can from the environment a vacuum of $5 \mathrm{kPa}$ was maintained in the stainless can using an oil-free scroll pump (Varian - SH110). The purpose of the copper can was to establish a near isothermal boundary around the equilibrium cell. To maximize its internal temperature uniformity, the copper can was charged with helium at $0.15 \mathrm{MPa}$. The temperature of the copper can was regulated using several thermofoil heaters (Minco Etched-foil Heaters) attached using high thermal conductivity epoxy (Stycast 2850 FT from CMR-Direct) at various locations around the can's exterior surfaces. Temperature sensors (100 $\Omega$ PRTs) were also mounted on the copper can next to the thermofoil heaters using epoxy to provide the feedback needed by the controller regulating the can's temperature. Liquid nitrogen was 
transferred to the Dewar in which the stainless steel can was suspended via a remotely controlled micro-dosing system (Norhof Series 900), which included a dosing pump, 100liter tank, heaters, level sensor and controller.

To charge the cell with the desired amount of solute (liquid phase) and solvent (gas or liquid), two high precision syringe pumps (Teledyne ISCO 260D) were employed: these could deliver flow rates ranging from 0.001 to $107 \mathrm{ml} \cdot \mathrm{min}^{-1}$ under controlled pressures ranging from 0.07 to $52 \mathrm{MPa}$. Both syringe pumps were equipped with a temperature control jacket in which distilled water was continuously circulated at a constant temperature of $298.15 \mathrm{~K}$ via a connected benchtop chiller (PolyScience LM6) with temperature range of 263-303 K and $\pm 0.1 \mathrm{~K}$ stability. Both syringe pumps could be isolated with two high-pressure needle valves (from High Pressure Equipment Co.). 


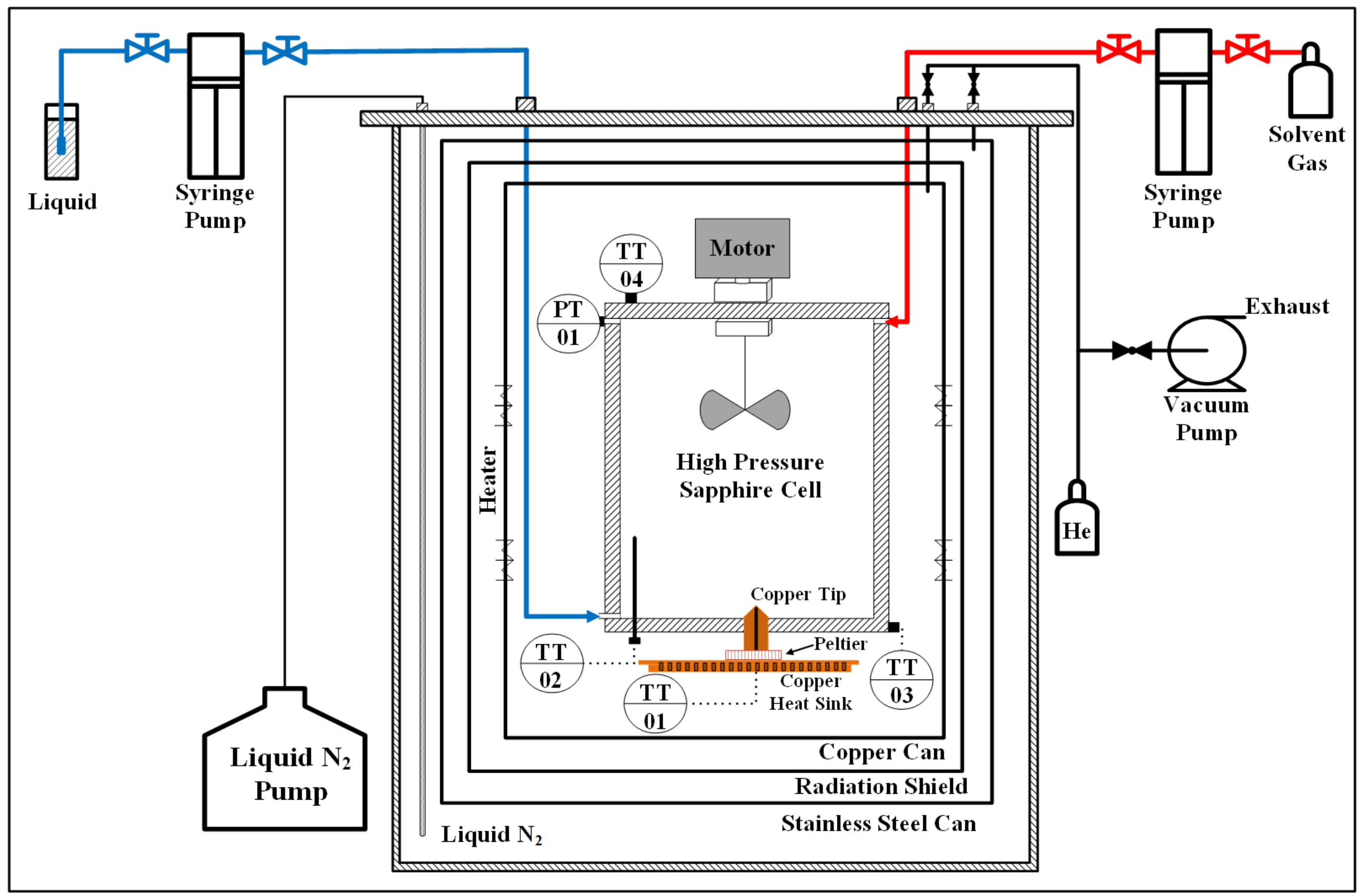

Figure 1. Schematic diagram of the CryoSolids apparatus (not to scale). The labels are described in the text. For clarity the periscopes used for visualisation are not shown here. 


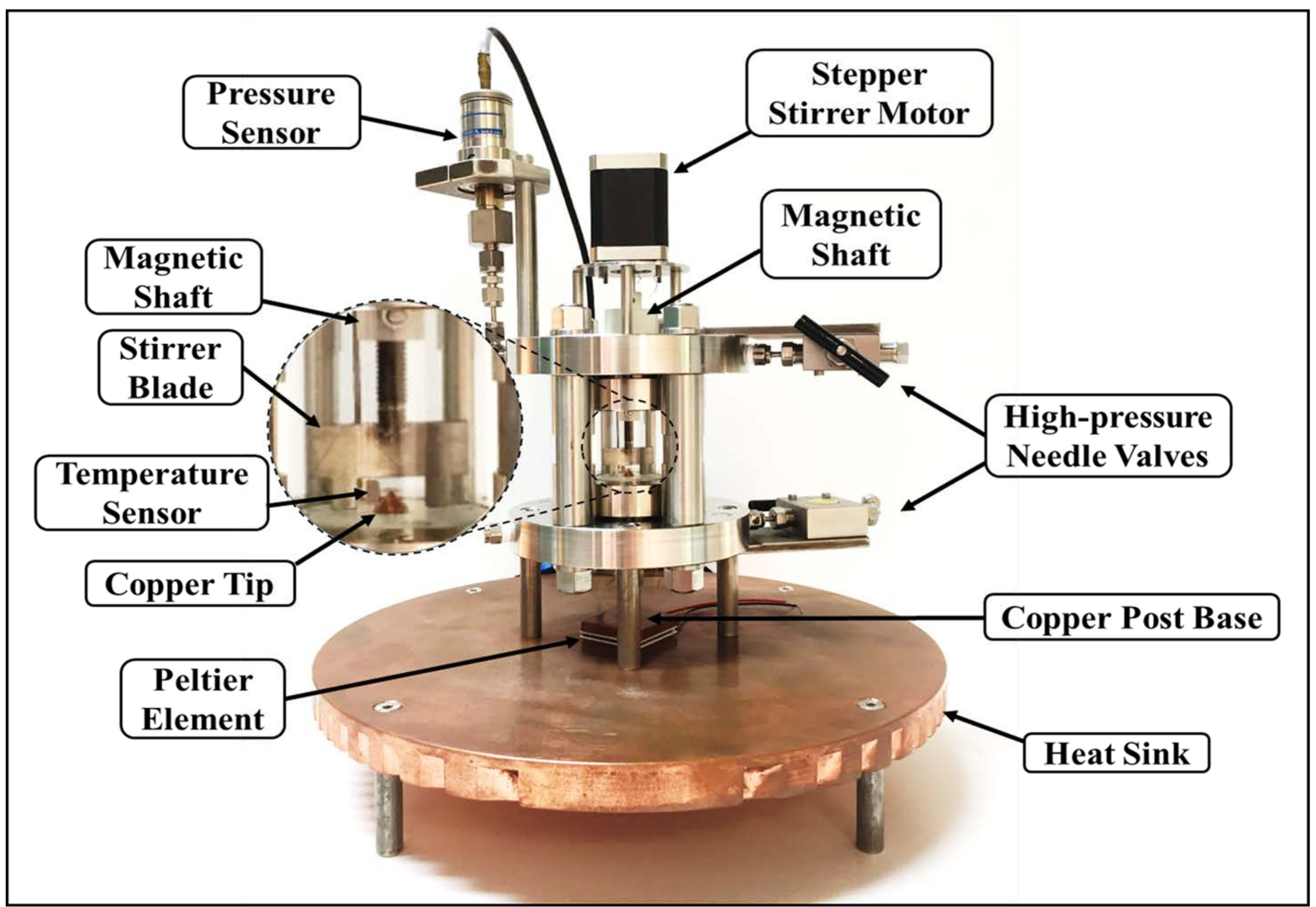

Figure 2. Image of the high pressure equilibrium sapphire cell with its key features. 


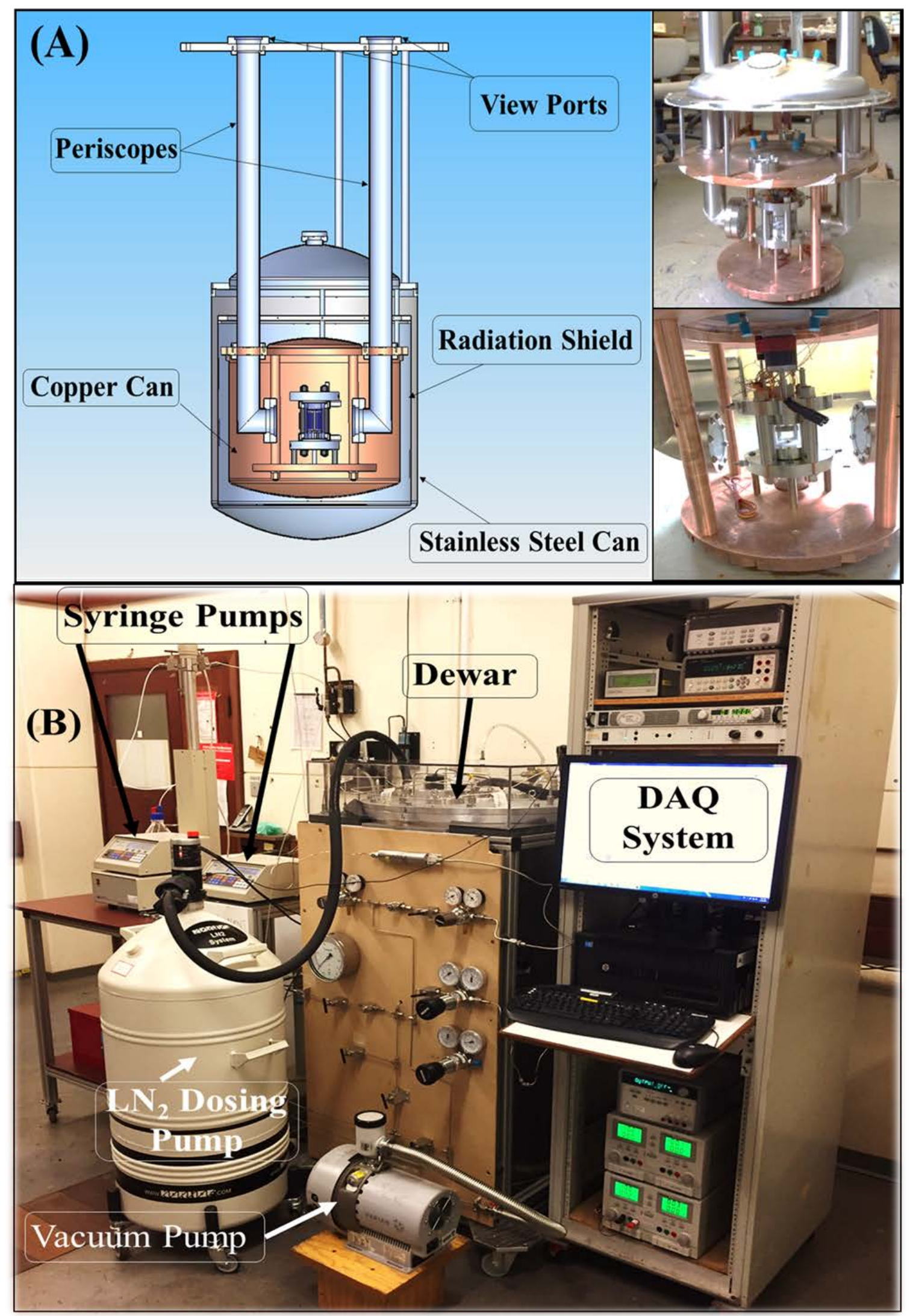

Figure 3. Experimental setup used to control and record the experiments: (A) High pressure sapphire cell placed inside the cryogenic thermostat with two periscopes shown, and (B) the front view of the assembled apparatus. 
To accurately determine the melting (or liquidus) temperatures, solids were forced to form on and disappear from a small surface area at a known location, namely the tip of a copper element also comprising a post and a base. The tip was immersed within the high-pressure liquid mixture, while the post led to the exterior of the visual cell via a swaged ferrule that provided a seal. The base of the copper post was attached to a $40 \times 40 \mathrm{~mm}$ Peltier module (CP10-127-05-L1 model from Laird Technologies) used to apply a specified cooling or heating rate to the copper tip. A DC power supply (Keysight LXI- N5750A) controlled by a proportional-integral algorithm was used to drive the Peltier element. The heat extracted by the Peltier module was dissipated to the helium atmosphere within the copper can via a large disc-shaped copper heat sink (35cm OD) with finned base attached to the other side of the Peltier.

To capture precisely the temperature at which melting occurred, a fast-response $100 \Omega$ platinum resistance thermometer (NR-141from Netsushin, Japan), labelled in Figure 1 as TT01, was inserted into the copper post to monitor the temperature of the copper element's tip. Three similar temperature sensors (TT02-TT04) were also used to capture the temperature of the bulk liquid inside the cell and to monitor the cell's temperature gradients. All PRTs were calibrated over a temperature range of 77 to $340 \mathrm{~K}$ using a reference standard PRT sensor (ASL-WIKA) with a standard uncertainty of $0.02 \mathrm{~K}$. In this work, the reported melting temperature corresponds to the reading of the PRT (TT01) inserted inside the copper post at the moment the last solid crystal on the tip was observed to disappear. At a scan rate of $0.01 \mathrm{~K} \cdot \mathrm{min}^{-1}$ the observed melting temperature differed negligibly from one obtained by extrapolating to a scan rate of zero [6], with any difference being much smaller than the estimated uncertainty of the temperature measurement (discussed below).

A stepper motor mixer (Arun Microelectronics D42.2) was used to homogenise the mixture under study. The motor shaft and the stirrer blade were magnetically coupled and controlled via an SMD210 dual stepper motor controller. A pressure transducer (Kyowa PHB-A-50MP) designed for operation at cryogenic temperatures, was used to monitor the fluid pressure. The transducer features a strain gauge with a hermetically-sealed structure filled with an inert gas, ensuring good linearity and thermal characteristics. The pressure transducer was calibrated in-situ at different temperatures against a reference quartz-crystal transducer (Paroscientific Digiquartz 9000-6K-101) with estimated standard uncertainty of $0.2 \%$ of the reading above 1 MPa. 


\subsection{Materials}

The chemicals used in this work have been summarized in Table 3, together with their sources and purities as specified by the suppliers. They were used without further purification: however, upon loading of the solute prior to the start of each mixture measurement, the liquid was degassed by evacuating any dissolved gas present using a vacuum pump (Vacuubrand MZ2C), to lower the pressure to $0.7 \mathrm{kPa}$.

Table 3. Chemicals used in this work with their corresponding purities as specified by the supplier.

\begin{tabular}{ccccc}
\hline Chemical Name & Source (Product Number) & Grade & $\begin{array}{c}\text { Mole Fraction } \\
\text { Purity }\end{array}$ & CAS Number \\
\hline Methane $\left(\mathrm{CH}_{4}\right)$ & Coregas Australia & 4.5 & $>0.99995$ & $74-82-8$ \\
Ethane $\left(\mathrm{C}_{2} \mathrm{H}_{6}\right)$ & Coregas Australia & 4.0 & $>0.9999$ & $74-84-0$ \\
p-Xylene $\left(\mathrm{C}_{8} \mathrm{H}_{10}\right)^{\mathrm{a}}$ & Sigma Aldrich (317195) & HPLC & 0.998 & $106-42-3$ \\
\hline
\end{tabular}

${ }^{a}$ The batch number used for $p$-Xylene was SHBG4724V.

\subsection{Uncertainties and calibration experiments}

The CryoSolid apparatus generates measurements of melting (liquidus) temperature $\left(T_{\text {melt }}\right)$, pressure $(p)$, and the composition $(x)$. A detailed assessment of the experimental uncertainties in each of these quantities was provided in our previous work [6]. To summarize, the standard combined uncertainty in the solvent mole fractions of either methane $u\left(\boldsymbol{x}_{\mathbf{C}_{1}}\right)$ or ethane $u\left(\boldsymbol{x}_{\mathbf{C}_{2}}\right)$ and the $p$-xylene solute $u\left(\boldsymbol{x}_{\mathbf{C}_{\mathrm{pxy}}}\right)$ were estimated by combining in quadrature the uncertainties arising from the syringe pump (ISCO) injections (volume, pressure, and temperature), dead volumes of the liquid and gas injection lines, and the purity of the chemicals used in this study together with the propagated uncertainties of the pressure and temperature sensors. The total available cell volume was $55.3( \pm 0.3) \mathrm{mL}$ (determined from volumetric calibration experiments conducted in-situ with pure water using the syringe pump) and the volume of liquid present in the cell could be determined from the level of the vapour-liquid interface within $0.6 \mathrm{~mL}$.

The standard uncertainty of the measured melting temperatures, $u\left(T_{\text {melt }}\right)$, determined using the TT01 sensor was estimated by combining in quadrature the standard deviation of three 
repeat measurements with the standard uncertainty of the thermometer's calibration $(0.019$ K). The standard deviations stemming from repetition of the measurement (typically around $0.15 \mathrm{~K}$ ) were the most significant source of uncertainty in the melting temperature measurements.

A Kyowa pressure transducer (PT01), rated for measurements over the range of (0.1 - 50 $\mathrm{MPa}$ ) was employed for the pressure measurements. When excited with a constant 5 VDC power source (as recommend by the manufacturer), the pressure transducer produced a voltage output that varied linearly with the system pressure. However, when compared with the reference Paroscientific pressure transducer, some variations in the voltage reading obtained at different temperatures were observed even though the manufacturer stated the transducer to be temperature-compensated. Accordingly, an in-situ calibration was carried out at pressures from $(0.1-35) \mathrm{MPa}$ over the temperature range $(100-350) \mathrm{K}$ by comparison of the PT-01 reading with that of the reference Paroscientific transducer (which was at ambient temperature). The root mean square (r.m.s.) deviation from the Paroscientific transducer readings following calibration of the PT-01 sensor was $3.2 \mathrm{kPa}$. The Kyowa pressure transducer uncertainty, $u(p)$, was estimated by combining in quadrature the manufacturer's stated uncertainty ( $0.2 \%$ of the reading), the r.m.s. deviation of the transducer's calibration $(3.2 \mathrm{kPa})$, and the standard deviation of three repeat measurements (typically around $20 \mathrm{kPa}$ ).

After the calibration was completed, the Kyowa transducer pressure readings were validated by measuring the saturation pressures of pure methane and ethane over a range of temperatures. This provided a consistency check between the calibrated temperature sensor and the calibrated pressure sensor. Figure 4 depicts the measured saturation pressures for methane and ethane together with their deviation plots. The corresponding saturation pressures were calculated from the measured cell temperature using the reference equations of state (EOS) for methane and ethane [42, 43] implemented in the software package NIST REFPROP 9.1 [44] The measured and calculated saturations are compared in Figure 4, which shows deviation plots for the methane and ethane measurements. The measured saturation pressures produced an r.m.s value of $19.4 \mathrm{kPa}$ for pure methane and $13.3 \mathrm{kPa}$ for pure ethane. These are consistent with the combined uncertainty of the pressure measurement given the 20 $\mathrm{kPa}$ standard uncertainty of the pressure and the $5 \mathrm{kPa}$ due to the standard uncertainty of the thermometer $(0.15 \mathrm{~K})$. 

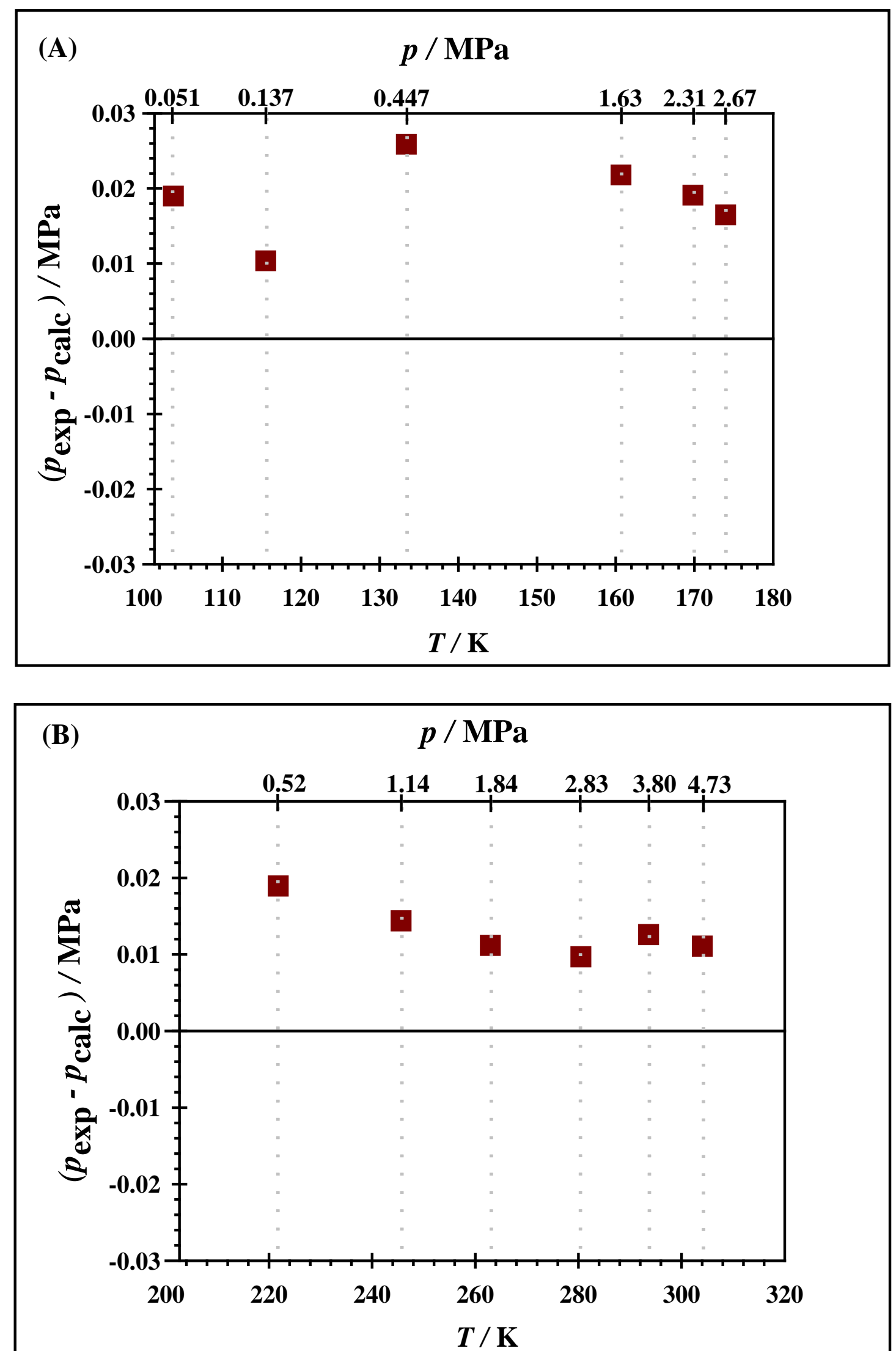

Figure 4. Deviations of the measured saturation pressure for (A) methane and (B) ethane from the calculation using respective reference EOS as implemented in REFPROP 9.1. 


\subsection{Melting temperature measurement procedure}

Most of the melting temperature measurements for the methane $+p$-xylene binary were made using the incubation air-bath system described by Siahvashi et al. [6] because the melting in that system occurred at temperatures above $273 \mathrm{~K}$. One of the methane $+p$-xylene melting temperature measurements were made using the Cryosolids apparatus to test the consistency of results obtained using the two instruments. All of the ethane $+p$-xylene measurements were made using the Cryosolids apparatus, the operation of which is detailed below.

To prepare the apparatus for measurement, the internal space between the Dewar wall and the stainless steel can was first evacuated to avoid any condensation or ice formation that may occur upon the dosing of liquid nitrogen. Similarly, the copper can, stainless steel can, and the periscope housings were evacuated followed by the introduction of helium to the copper can and periscopes (only). The equilibrium cell was pre-cleaned using appropriate solvents followed by evacuation and then the injection of the desired amount of solute liquid ( $p$ xylene) into the bottom of the equilibrium cell at around ambient temperature. The liquid $p$ xylene was degassed prior to its loading into the syringe pump. To ensure that the liquid $p$ xylene injected into the equilibrium cell remained free of any dissolved air, the degassing procedure was repeated in-situ with the equilibrium cell under vacuum and the stirrer on. (The low vapour pressure of p-xylene 575 Pa meant this evacuation caused only a negligible reduction in the amount of p-xylene in the cell.) Subsequently, the solvent gas (methane or ethane) was injected into the top of the equilibrium cell using the other syringe pump. The volumes injected were chosen to achieve the composition desired for the syntheticallyprepared mixture, after which vigorous mixing was applied to the sample for equilibration.

Liquid nitrogen was then introduced into the Dewar using the dosing pump, causing the system temperature to decrease. The temperatures of the copper can and the equilibrium cell were ultimately stabilised at the desired temperature set-points automatically by their respective heaters and control algorithms. The bulk liquid temperature in the cell, measured by sensor TT02, was then reduced in steps by adjusting the copper can temperature set point to about 0.5 to $1.0 \mathrm{~K}$ above the estimated melting point. Once the bulk liquid temperature sensor had stabilised, the copper post temperature was reduced automatically with the Peltier element at a scan rate of $0.01 \mathrm{~K} \cdot \mathrm{min}^{-1}$, which was shown to introduce negligible thermal lag by Siahvashi et al. [6] This induced a solid phase to eventually freeze out on the tip of the 
copper element as it cooled slightly relative to the bulk. Following the freeze-out, the temperature at the tip of the copper element (measured by TT01) was increased at the same scan rate to the point where all solids disappeared. Throughout the heating ramp, the stirrer bar was actuated at 300 RPM for a period of 30 seconds once every 30 seconds to ensure that the liquid phase mixture remained homogeneous as the solids melted. A camcorder (JVC, Everio 40x) located on the top of one of the periscope viewing windows in the Dewar lid recorded the image of the equilibrium cell including the copper post. Additional light was provided by LED strips installed inside the copper can, which provided the background light necessary for the camera to be able to zoom and focus to achieve a high quality image. To avoid any condensation of air moisture on the external view ports in the Dewar lid, dry air was continuously circulated across them.

In many experiments we observed that the subcooling required to nucleate the solid phase in a subsequent cycle decreased if the previous heating ramp did not extend far enough into the fluid phase region. Such a phenomenon has been reported in studies of gas hydrate formation (e.g. [45]) where it likely reflects a local supersaturation of guest molecules in the aqueous phase following dissociation of the crystal. In this experiment we hypothesise that it was caused by an increased local concentration of p-xylene in the liquid near the surface of the copper tip, resulting from the melting of the solid phase. To avoid this, for each repeat melting temperature measurement the entire system including the Dewar, copper can, cell and bulk liquid was first heated to about 7-10 $\mathrm{K}$ above the measured equilibrium temperature and then cooled down to their original temperatures.

\section{Results and Discussion}

\subsection{Vapour-liquid equilibrium (VLE) measurements of $C_{1}+C_{p x y}$.}

This mixtures studied in this work were prepared in-situ using the synthetic technique, where the overall composition is determined through the injection of known amounts of solute and solvent to the equilibrium cell. This approach gives a well-defined equilibrium composition for the fluid mixture at the melting temperature if at that moment only a single-phase liquid or a single-phase gas is present. However, the $\mathrm{C}_{1}+\mathrm{C}_{\mathrm{pxy}}$ measurements occurred at conditions well above methane's critical temperature, and thus a vapour-liquid equilibrium condition existed prior to solidification. With no ability to sample and analyse the composition of either 
fluid phase, the partitioning of the methane and p-xylene components across the vapour and liquid phases were volumetrically estimated and then compared with the calculations from an equation of state tuned to VLE data for this binary reported in the literature [46].

The in-situ mixture preparation began with the injection of pure $p$-xylene as a liquid to the evacuated cell using the syringe pump. The $p$-xylene in the syringe pump was controlled at a known temperature and pressure, which allowed the total number of moles injected to the cell to be calculated from the displaced volume and the liquid density calculated via the reference EOS for p-xylene developed by Zhou et al. [47] as implemented in the software REFPROP 9.1 [44]. Methane was then introduced through the top of the cell from the other syringe pump; the number of moles injected was determined from measurements of the syringe pump temperature, pressure and volume before and after the transfer, using the reference EOS of Setzmann and Wagner [42].

The results of the liquid phase methane mole fractions determined at $293.15 \mathrm{~K}$ using the volumetric method are listed in Table 4 . The vapour pressure of $p$-xylene was estimated using the reference EOS of Zhou et al. [47]: at $293.15 \mathrm{~K}$ it was $0.88 \mathrm{kPa}$ and thus the mole fraction of $p$-xylene in the vapour phase was always less than 0.0002 , which is an order of magnitude below the experimental uncertainty of the liquid phase mole fractions determined using the volumetric method at pressures of 3.5 $\mathrm{MPa}$ and above.

These results were compared and found to be consistent with the only VLE data we are aware of for this system measured by Stepanova and Velikovskii [46] at $293.15 \mathrm{~K}$, as shown in Figure 5. Also shown are comparisons with bubble-pressure predictions made using the Peng Robinson EOS implemented in the software ThermoFAST [4]. Figure 5(A) shows predictions made using a binary interaction parameter (BIP) for methane $+p$-xylene calculated using a group contribution method derived by Vitu et al. [48].

Also shown are bubble points calculated after tuning the BIP to force agreement with the available data. This tuning of the BIP used decreased the root mean square (r.m.s) deviation of the data (this work and ref. [46]) from the predicted bubble points, using the group contribution BIP, from 2.85 MPa to 0.15 MPa. This tuned Peng Robinson EOS was used to calculate the composition of the liquid phase in the methane $+p$-xylene SLVE measurements with an estimated uncertainty, $u\left(\boldsymbol{x}_{\mathbf{C}_{1}}\right)$ of 0.0025 ; the small extrapolation in temperature from $293 \mathrm{~K}$ where the VLE data were measured to (286 to 277) K where the SLVE temperatures were measured was assumed to have a negligible impact on this uncertainty. 

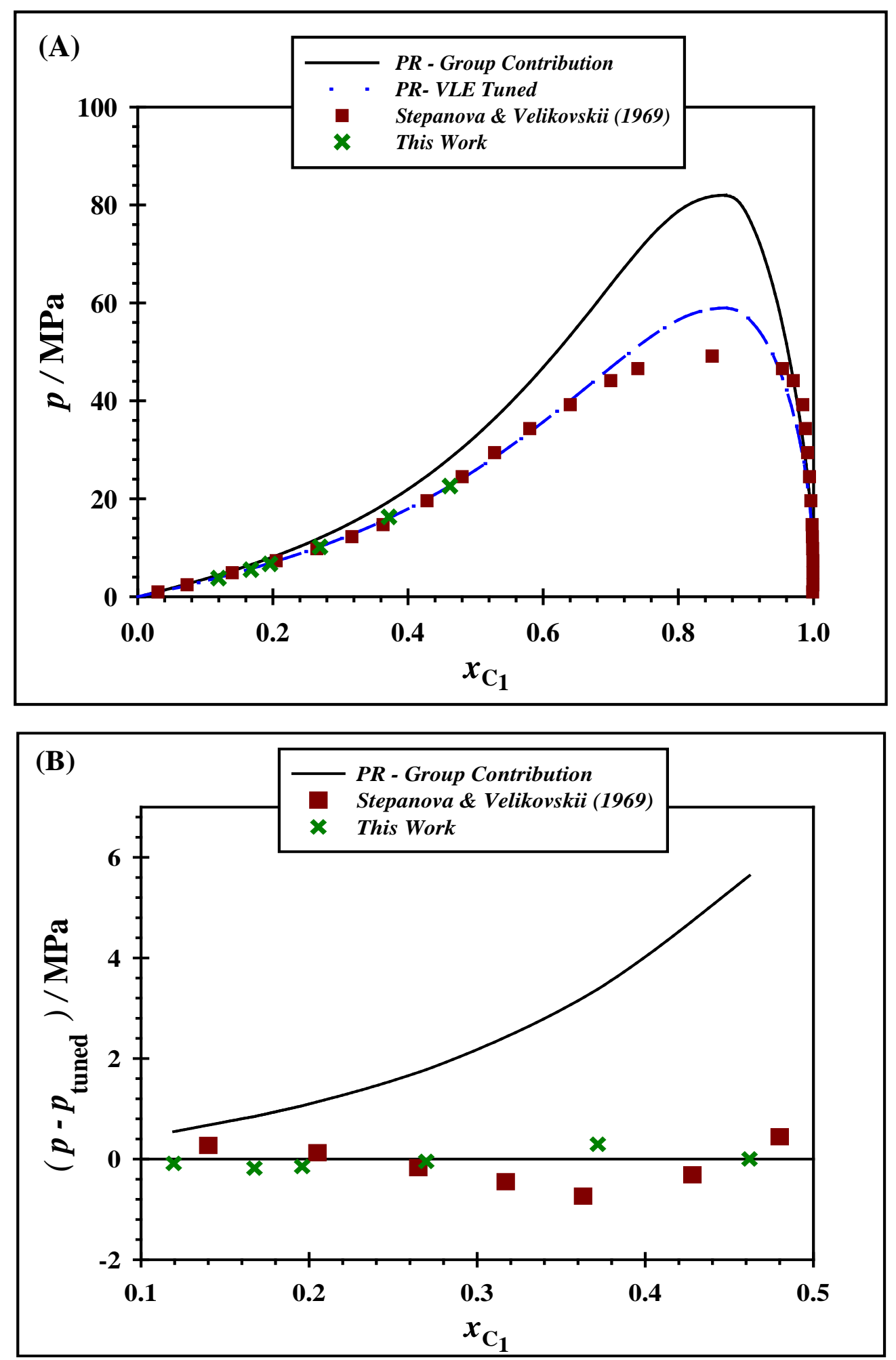

Figure 5. (A) Measurements of methane $+p$-xylene vapour liquid equilibrium at $293.15 \mathrm{~K}$ made in this work and reported by Stepanova and Velikovskii [46] together with values calculated with the Peng Robinson (PR) equation of state using a binary interaction parameter (BIP) either estimated by a group contribution method [48] or tuned to the measured VLE data. (B) Deviations from the bubble-pressure calculated using the PR EOS with the VLE- 
tuned BIP, $p_{\text {tuned, }}$ of the measurements and of the values calculated using the group contribution binary interaction parameter. The experimental uncertainties are too small to be shown as error bars in these plots but are listed in Table 4.

Table 4. Experimental $p$ - $x$ results for methane $+p$-xylene binary system at vapour-liquid equilibrium with their associated standard uncertainties at $293.15 \mathrm{~K}^{\mathrm{a}}$

\begin{tabular}{cccc}
\hline $\boldsymbol{x}_{\mathrm{C}_{1}}$ & $\boldsymbol{u}\left(\boldsymbol{x}_{\mathrm{C}_{1}}\right)$ & $\boldsymbol{p} / \mathbf{M P a}$ & $\boldsymbol{u}(\boldsymbol{p}) / \mathbf{M P a}$ \\
\hline 0.1195 & 0.0031 & 3.79 & 0.03 \\
0.1675 & 0.0043 & 5.50 & 0.02 \\
0.1959 & 0.0036 & 6.69 & 0.03 \\
0.2697 & 0.0049 & 10.16 & 0.04 \\
0.3718 & 0.0032 & 16.30 & 0.04 \\
0.4620 & 0.0028 & 22.58 & 0.03 \\
${ }^{a}$ The standard uncertainty in temperature was $0.15 \mathrm{~K}$.
\end{tabular}

\subsection{Solid -liquid -vapour equilibrium ( $S L V E$ ) measurements of $C_{1}+C_{p x y}$.}

Prior to the commencement of the melting (liquidus) temperature measurements for the binary mixture, the melting temperature of pure $p$-xylene was measured at its vapour pressure. Since this vapour pressure was lower than the pressure transducer's resolution, it was estimated to be $0.58 \mathrm{kPa}$ using the reference EOS [47]. Then methane was dosed into the cell to a final pressure of 1.51 MPa upon equilibration, corresponding to a liquid methane mole fraction of 0.055, and the melting temperature was measured for the mixture. Figure 6 shows photographs which contrast measurements made with a mixture (liquid phase methane mole fraction of 0.1165 ) and with a pure substance. In particular for pure $p$-xylene the solid formed on the copper tip was very clear in comparison with the solid formed when methane was present in the system. These images (captured by the 10x CCD camera) reveal a qualitative difference in the crystallization morphology observed for the mixture as compared to that observed for the pure $p$-xylene. We hypothesise that the reason for this difference in morphology is that the crystallisation of $p$-xylene from the solution causes the liquid phase to become locally over-saturated with methane. The over-saturation causes the formation of small bubbles of methane, some of which are initially trapped within the solid crystal mesh and cannot readily mix with the bulk liquid. However, this difference in morphology did not influence the measured melting temperatures because the act of increasing the copper tip temperature to approach the equilibrium condition always caused any trapped methane gas bubbles to disappear prior to the final crystal melting (as illustrated in Figure 7). 


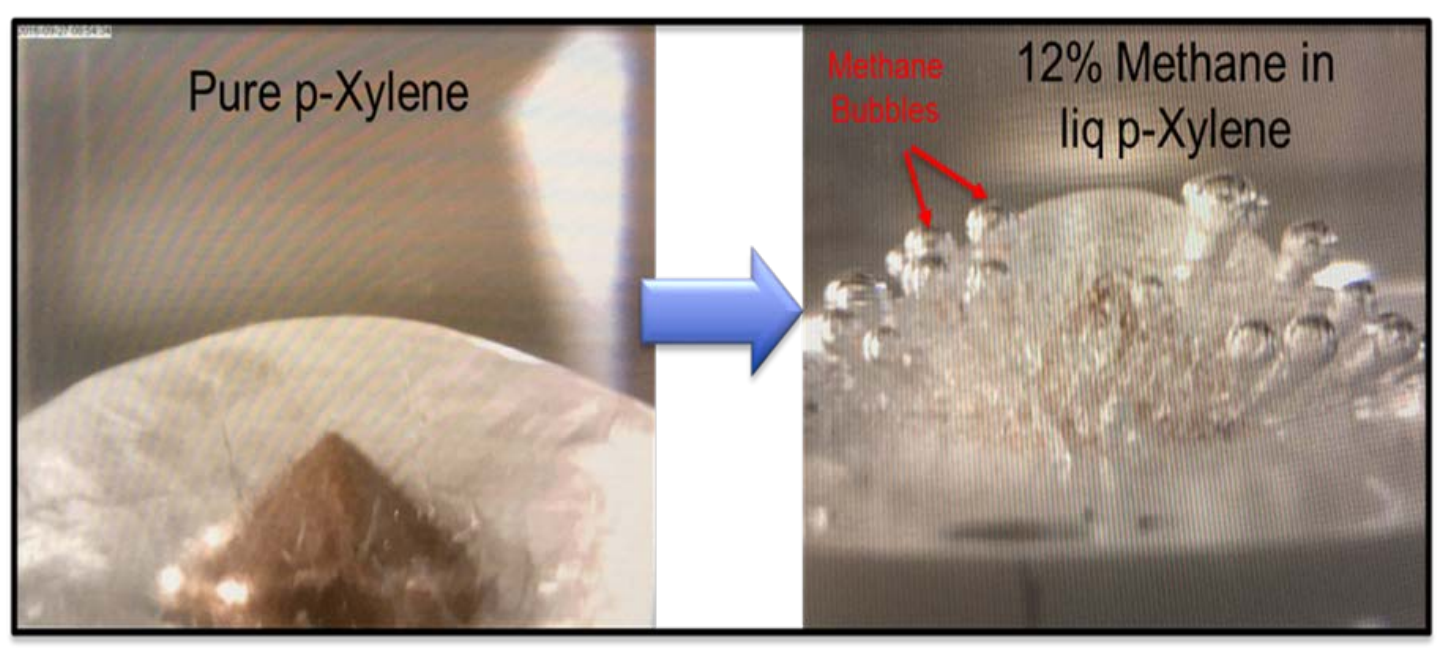

Figure 6. CCD camera image of solid formation in pure $p$-xylene (left) and from a binary liquid mixture of $0.1165 \mathrm{C}_{1}+0.8835 \mathrm{C}_{\mathrm{pxy}}$ (right).

The freezing and melting of solid $p$-xylene from a system where the liquid composition was $0.42 C_{1}+0.58 C_{p x y}$ is shown in Figure 7, with the images captured over an 8-minute period while the system was under continuous stirring. These images indicate that some of the methane gas dissolved in the liquid p-xylene became trapped or temporarily adhered to the solid-liquid interface upon initial solid formation. As formation continued, the bubbles on the surface of the solid phase appeared to increase in size as trapped gas diffused out of solid. Eventually these enlarged bubbles detached and rose upwards to the bulk vapour liquid interface.

The results of the SLVE measurements for binary mixtures of methane and p-xylene as a function of liquid phase methane mole fraction and pressure are listed in Table 5 and shown in Figure 8. Increasing the pressure to $22.5 \mathrm{MPa}$ increased the methane mole fraction in the liquid to 0.42 and depressed the melting temperature relative to pure $p$-xylene by $8.6 \mathrm{~K}$. The impact of calculating the melting temperature using the PR EOS model in ThermoFAST using three different binary interaction parameters is also shown in Figure 8: of most significance, the binary interaction parameters obtained by tuning to the measured VLE data and by a group contribution method under-predict the measured SLVE melting temperatures with r.m.s. deviations of $3.1 \mathrm{~K}$ and $2.5 \mathrm{~K}$, respectively. A significantly improved representation of the data can be achieved by adjusting the binary interaction parameter to force agreement with the SLVE data. Such tuning decreases the r.m.s. deviation of the measured melting temperatures from those predicted with the PR EOS to $0.4 \mathrm{~K}$. 


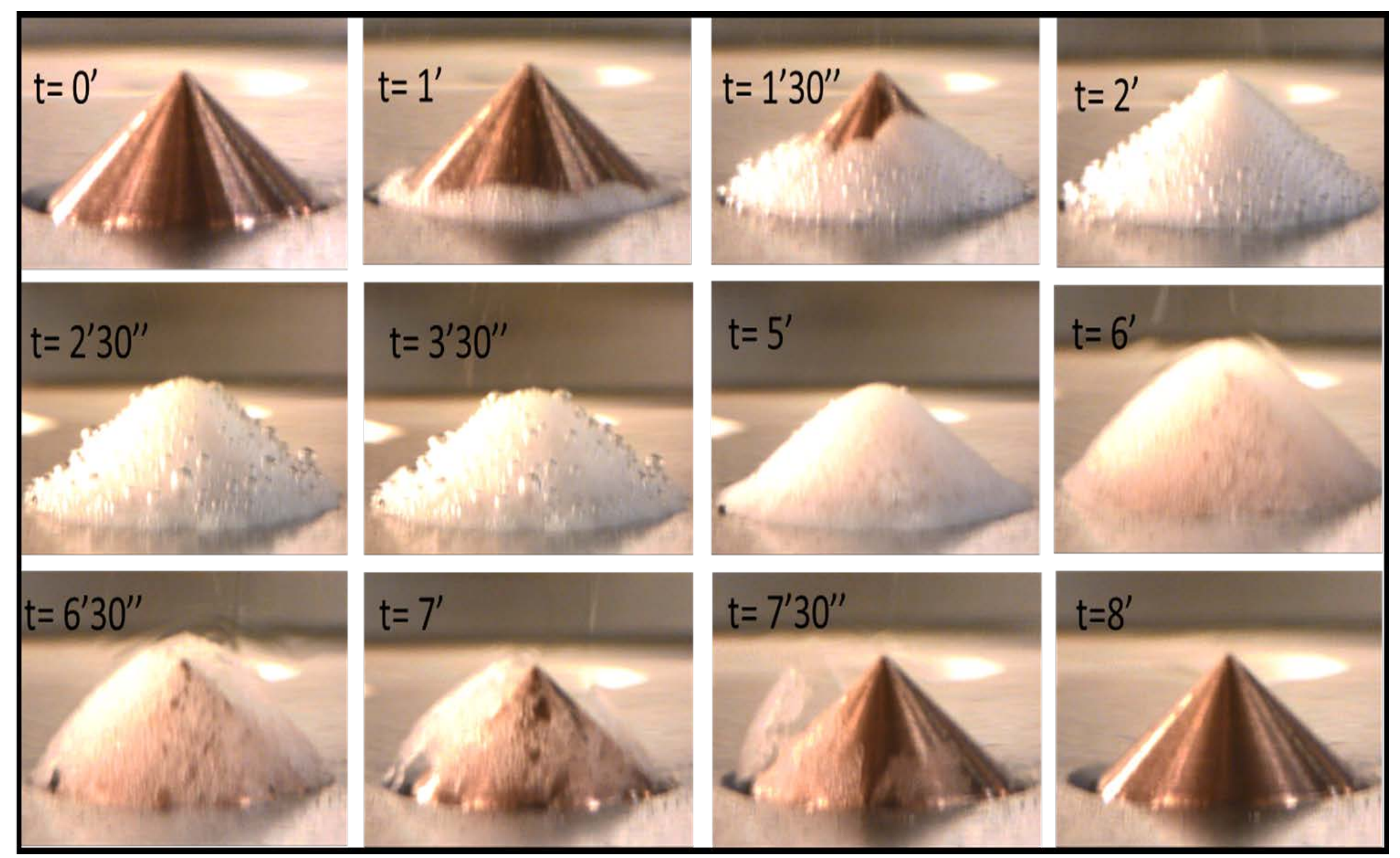

Figure 7. An example of CCD images taken at 10x magnification of the freezing and melting of $p$-xylene from a liquid mixture of $0.42 \mathrm{C}_{1}+0.58 \mathrm{C}_{\mathrm{pxy}}$. The bulk liquid temperature was kept constant at $278.5 \mathrm{~K}$ while the copper tip temperature was reduced to around $276 \mathrm{~K}$ to induce nucleation before reaching the equilibrium melting temperature of $277.7 \mathrm{~K}$. 

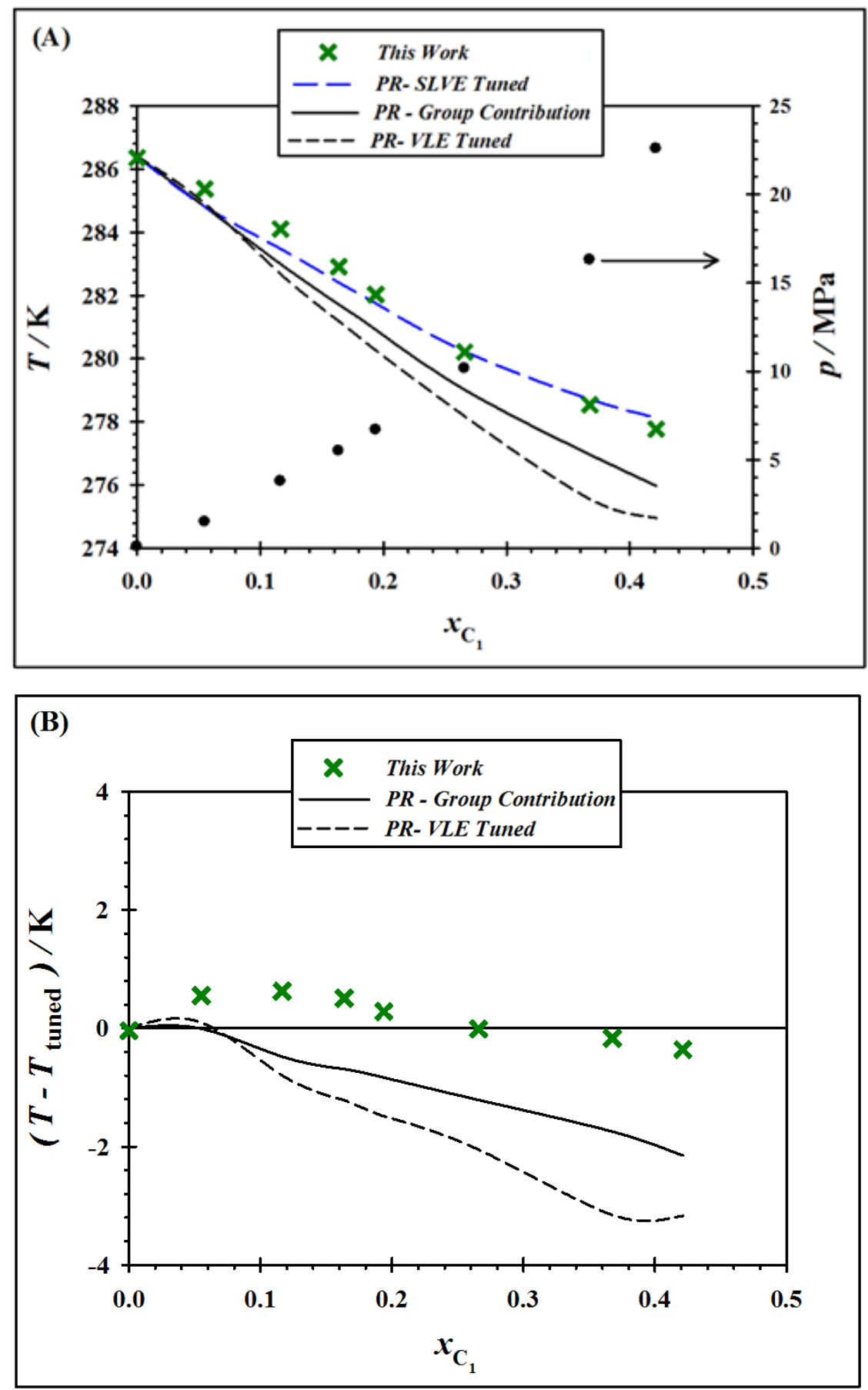

Figure 8. (A) Melting temperatures of $\mathrm{C}_{1}+\mathrm{C}_{\mathrm{pxy}}$ mixtures and their corresponding pressures at SLVE as a function of mole fraction of methane in the liquid phase, together with values calculated using the Peng Robinson EOS with three different binary interaction parameters (BIPs): group contribution, VLE-tuned, and SLVE-tuned. (B) Deviations from melting temperatures calculated using the SLVE-tuned BIP, $T_{\text {tuned }}$, of the measured melting temperature data and of values calculated using the VLE-tuned and group contribution BIPs. 
Table 5. Measured SLVE data for the $\mathrm{C}_{1}+\mathrm{C}_{\mathrm{pxy}}$ binary mixture, where $\mathbf{z}_{\boldsymbol{c}_{1}}$ is the overall methane mole fraction in the equilibrium cell determined from the mixture preparation, $x_{1}$ is the mole fraction of methane in the liquid phase calculated from PR EOS tuned to the VLE data shown in Figure 5.

\begin{tabular}{|c|c|c|c|c|c|c|c|}
\hline $\mathbf{z}_{\mathrm{C}_{1}}$ & $u\left(\mathbf{z}_{\mathrm{C}_{1}}\right)$ & $x_{\mathbf{C}_{1}}$ & $u\left(x_{\mathrm{C}_{1}}\right)$ & p/MPa & $u(p) / \mathbf{M P a}$ & $T_{\text {melt }} / \mathbf{K}$ & $\begin{array}{c}u\left(T_{\text {melt }}\right) / \\
\mathbf{K}\end{array}$ \\
\hline 0.0000 & - & 0.0000 & - & $5.8 \times 10^{-4 a}$ & - & 286.36 & 0.08 \\
\hline 0.1309 & 0.0018 & 0.0550 & 0.0035 & 1.51 & 0.02 & 285.37 & 0.28 \\
\hline 0.2701 & 0.0016 & 0.1165 & 0.0029 & 3.70 & 0.03 & 284.11 & 0.30 \\
\hline 0.3622 & 0.0015 & 0.1638 & 0.0041 & 5.52 & 0.04 & 282.91 & 0.18 \\
\hline 0.4173 & 0.0021 & 0.1938 & 0.0037 & 6.61 & 0.02 & 282.03 & 0.16 \\
\hline 0.5117 & 0.0019 & 0.2659 & 0.0033 & 10.1 & 0.03 & 280.21 & 0.21 \\
\hline 0.6357 & 0.0018 & 0.3675 & 0.0030 & 16.3 & 0.02 & 278.54 & 0.23 \\
\hline 0.6904 & 0.0017 & 0.4212 & 0.0032 & 22.5 & 0.03 & 277.77 & 0.19 \\
\hline
\end{tabular}

\subsection{SLE measurements of $C_{2}+C_{p x y}$.}

The CryoSolid apparatus was used to measure the SLE of the ethane $+p$-xylene system. As ethane's critical temperature is above that of pure $p$-xylene's melting temperature, it was possible to prepare a single phase liquid mixture with a synthetically determined composition, and avoid the uncertainty associated with the presence of a vapour phase. After loading a fixed volume of liquid p-xylene into the cell, the system was pressurised with ethane and stirred until a homogenous liquid phase formed. As the cell was cooled, additional ethane was injected as required to maintain a single liquid phase: increasing the ethane content of the mixture from a mole fraction of 0.79 to 0.94 allowed melting temperatures over the range (240 to 200 ) $\mathrm{K}$ to be measured. For SLE, melting temperatures are relatively insensitive to pressure and because the fluid mixture remained in the liquid phase it was relatively easy to vary the system pressure by a slight change in the injection pump volume. At the higher temperatures, reasonably large pressures (3.5 to $6 \mathrm{MPa}$ ) were applied to ensure a vapour phase did not form inadvertently. 
Figure 9 shows an example of the freezing and melting process of ethane $+p$-xylene binary system over a 15-minute period visualised through the periscopes fitted to the CryoSolid apparatus. Although the image quality is not as high as that obtained with the air-bath (Figure 7), localised bubble formation upon freezing is clearly evident. Upon reversal of the copper tip temperature for determination of the melting point, bubble formation ceased and the appearance of the crystal morphology changed slightly becoming clearer and slowly disappearing. Measured values of the SLE data acquired in this work for the ethane $+p$ xylene system are listed in Table 6 and shown in Figure 10.

Table 6. Measured SLE data for the single phase liquid $\mathrm{C}_{2}+\mathrm{C}_{\mathrm{pxy}}$ binary mixture, where $\mathbf{z}_{\mathrm{C}_{2}}$ is the mole fraction of ethane in the liquid phase determined from the mixture preparation.

\begin{tabular}{cccccc}
\hline $\mathbf{z}_{\mathbf{C}_{2}}$ & $\boldsymbol{u}\left(\mathbf{z}_{\mathbf{C}_{2}}\right)$ & $\boldsymbol{p} / \mathbf{M P a}$ & $\boldsymbol{u}(\boldsymbol{p}) / \mathbf{M P a}$ & $\boldsymbol{T}_{\text {melt }} / \mathbf{K}$ & $\boldsymbol{u}\left(\boldsymbol{T}_{\text {melt }}\right) / \mathbf{K}$ \\
\hline 0.7914 & 0.0053 & 3.53 & 0.04 & 239.64 & 0.37 \\
0.8049 & 0.0051 & 5.91 & 0.03 & 238.04 & 0.31 \\
0.9080 & 0.0047 & 0.57 & 0.05 & 222.26 & 0.38 \\
0.9203 & 0.0043 & 0.43 & 0.06 & 213.83 & 0.36 \\
0.9427 & 0.0041 & 0.48 & 0.05 & 200.84 & 0.32 \\
\hline
\end{tabular}




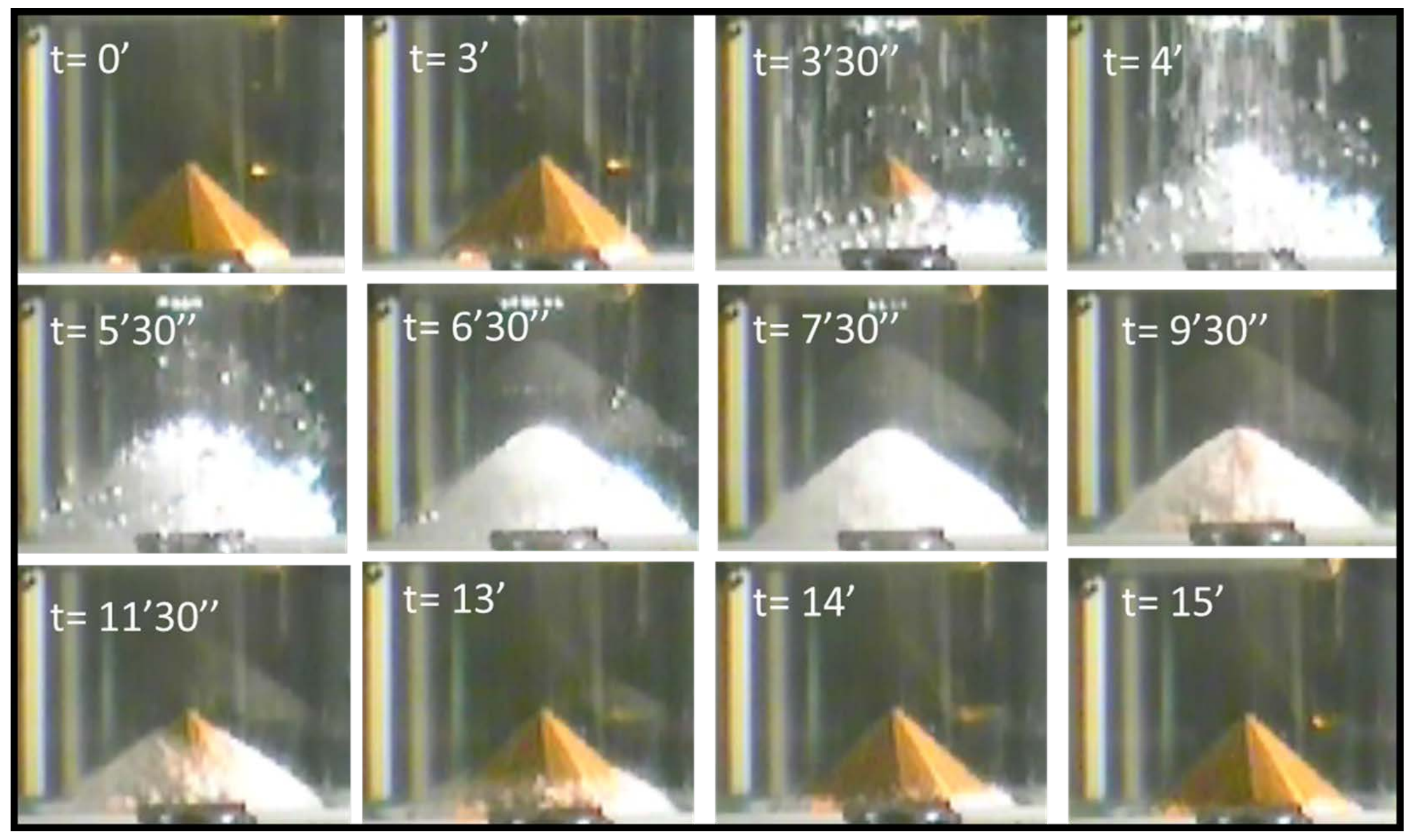

Figure 9. An example of the camcorder images taken through the periscopes of the Cryosolids apparatus showing the formation and melting of solid $p$-xylene from a liquid mixture of $0.7914 \mathrm{C}_{2}+0.2086 \mathrm{C}_{\mathrm{pxy}}$ at $3.5 \mathrm{MPa}$. The bulk liquid temperature was held constant at around $240.5 \mathrm{~K}$ while the copper tip temperature was reduced to around $238 \mathrm{~K}$ to induce nucleation before reaching the equilibrium melting temperature of $239.64 \mathrm{~K}$. 

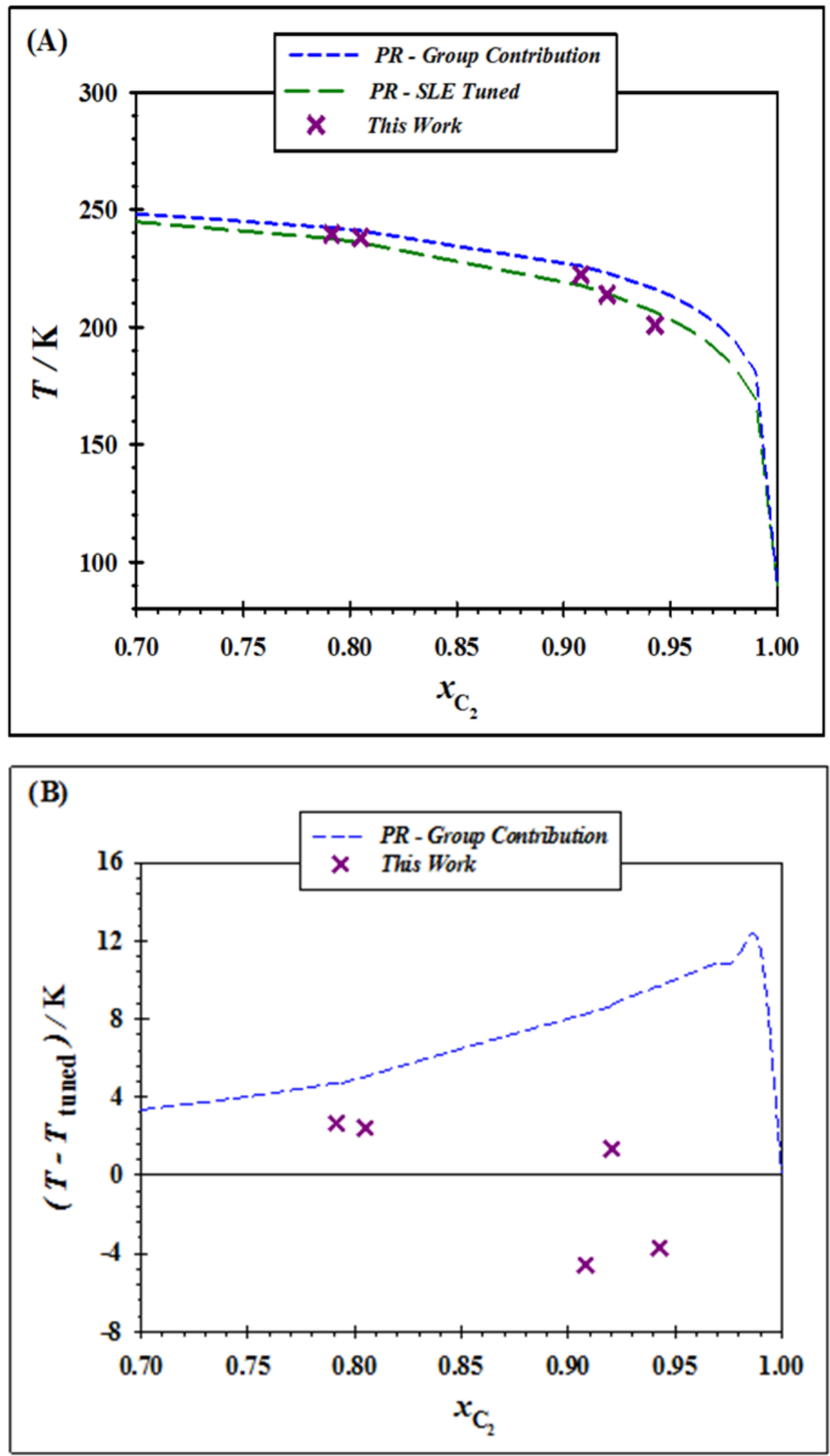

Figure 10. (A) Melting temperatures of $\mathrm{C}_{2}+\mathrm{C}_{\mathrm{pxy}}$ mixtures at SLE as a function of ethane mole fraction, together with values calculated using the Peng Robinson EOS with two different binary interaction parameters: group contribution and SLE-tuned. (B) Deviations from melting temperatures calculated using the SLE-tuned BIP, $T_{\text {tuned }}$, of the measured melting temperature data and of values calculated using the group contribution BIP. 
Similar to the $\mathrm{C}_{1}+\mathrm{C}_{\mathrm{pxy}}$ system, a group contribution method was first utilized to estimate an optimized BIP value to predict the SLE of the $\mathrm{C}_{2}+\mathrm{C}_{\mathrm{pxy}}$ system and compare with the experimental data measured in this work. As shown in Figure 10 (B), the BIP calculated using the group contribution method over-predicts the SLE melting temperatures by an r.m.s. value of $6.5 \mathrm{~K}$ (maximum over-prediction by $+12.4 \mathrm{~K}$ ) whereas the SLE-tuned BIP significantly reduced the deviations to an r.m.s. value of $3.1 \mathrm{~K}$ (maximum deviation of -4.5 $\mathrm{K})$.

\section{Conclusions}

Measurements of SLVE for $p$-xylene in methane were obtained for the first time using sapphire equilibrium cells fitted with a Peltier-cooled copper post at pressures to $22.5 \mathrm{MPa}$. To allow such measurements at cryogenic temperatures, one of the equilibrium cells was housed in a multi-stage thermostat contained within a Dewar and fitted with periscopes to allow visualiation of the solid formation and melting. This CryoSolid apparatus was used to measure SLE data for the $p$-xylene + ethane binary system for the first time at temperatures down to $200 \mathrm{~K}$ and pressures to $5.9 \mathrm{MPa}$. For both binaries, the overall mixture compositions were determined via the synthetic method. For the methane $+p$-xylene binary VLE data measured in this work and reported in the literature [46] were used to estimate the composition of the liquid phase at the observed SLVE conditions.

The melting temperature data obtained for these two binaries were compared with the predictions of the Peng Robinson EOS implemented in the software package ThermoFAST using a various binary interaction parameters which might be used by industry for estimating p-xylene solubility in LNG production. For both mixtures, a group contribution method [48] was used to estimate a binary interaction parameters, while for the methane $+p$-xylene system it was possible to also use a BIP tuned to the available VLE data to make melting temperature predictions. Tuned BIPs for predicting phase equilibria involving a solid phase were also obtained by forcing agreement between the measured data and the predictions of the cubic EOS. For methane $+p$-xylene, the VLE-tuned BIP led to a systematic underprediction of the melting temperature data with an r.m.s. deviation of $3.1 \mathrm{~K}$ while using the SLVE-tuned BIP allowed the EOS predictions to represent the data with an r.m.s. deviation of only 0.4 K. For ethane + p-xylene, the group contribution BIP produced a systematic overprediction of the melting temperature data with an r.m.s. error of $7.2 \mathrm{~K}$, which improved to 3.1 K upon tuning the BIP to the SLE data. These results for $p$-xylene are consistent with the 
finding reported previously $[4,6]$ that accurate solid-fluid phase equilibria calculations require different BIPs to those optimised for VLE calculations. This further indicates the need for additional measurements of melting temperatures in mixtures to improve models for the solubility of heavy compounds in hydrocarbon solvents.

A primary motivation of this work is to help improve the prediction of heavy hydrocarbon solubility in liquefied natural gas. At (4 MPa, $123 \mathrm{~K})$, which approximates the effluent condition of a main cryogenic heat exchanger in an LNG plant, benzene becomes insoluble in liquid methane at a mole fraction concentration of 8 parts-per-million [4]. While $p$-xylene is normally present at far lower concentrations in natural gas than benzene, it is also far less soluble in LNG and hence predicting whether any trace amount present is likely to be problematic can be crucial. Using the VLE-tuned BIP leads to a prediction of $0.8 \mathrm{ppm}$ for the solubility of $p$-xylene in liquid methane at (4 MPa, $123 \mathrm{~K}$ ). However, this predicted concentration drops to just $0.04 \mathrm{ppm}$ if the BIP is tuned to the melting temperature data measured in this work. Equivalently, for $p$-xylene in methane concentrations in the range (0.01 to 0.2) ppm, SLE temperature predictions at $4 \mathrm{MPa}$ made using the BIP tuned to the data reported here are (18 to 20) K higher than those obtained using the BIP tuned to VLE data for this binary. Such differences in the predictions of either allowable $p$-xylene concentration or allowable minimum temperatures for a given mixture have significant implications for the reliability of freeze-out risk assessments in LNG production, and emphasise the importance of extending the available data for heavy hydrocarbon solubility and improving the accuracy of predictive models.

\section{Acknowledgements}

The authors thank Craig Grimm for constructing the apparatus. This research was supported by Chevron and the Australian Research Council (IC150100019). 


\section{References}

[1] May EF, Guo JY, Oakley JH, Hughes TJ, Graham BF, Marsh KN, et al. Reference Quality Vapor-Liquid Equilibrium Data for the Binary Systems Methane + Ethane, + Propane, + Butane, and + 2-Methylpropane, at Temperatures from (203 to 273) K and Pressures to 9 MPa. J Chem Eng Data 2015;60:3606-20.

[2] Ismail SM, Khalifa AT. Unique Phenomenon of Moisture and Other Contaminants' Coalescence Under Cryogenic Conditions. Proceedings of LNG-18. Perth, Australia; 11-15 April 2016.

[3] Glasgow AR, Murphy ET, Willingham CB, Rossini FD. Purification, Purity and Freezing Points of 31 Hydrocarbons of the API-NBS Series. Research Paper [PR1734] Aug 1946;37(Department of Commerce National Bureau of Standards).

[4] Baker CJ, Oakley JH, Rowland D, Hughes TJ, Aman ZM, May EF. Rapid Simulation of Solid Deposition in Cryogenic Heat Exchangers To Improve Risk Management in Liquefied Natural Gas Production. Energy Fuels 2018;32:255-67.

[5] Finn; A, Farooq A. GPA Research Report RR-234: State of Art Survey for Heavy Hydrocarbon Removal and Disposition Associated with LNG Production Facilities. Gas Processors Association; 2017.

[6] Siahvashi A, Al-Ghafri SZS, Oakley JH, Hughes TJ, Graham BF, May EF. Visual Measurements of Solid-Liquid Equilibria and Induction Times for Cyclohexane + Octadecane Mixtures at Pressures to 5 MPa. J Chem Eng Data 2017;62:2896-910.

[7] Ott CM, Liu YN, Roberts M, Luo X, Chen F. Heavy Hydrocarbon Removal from Unconventional Natural Gas Feeds. GasTech. London; 2012.

[8] Design Institute for Physical Properties (DIPPR) 801 Database https://app.knovel.com/web/toc.v/cid:kpDIPPRPF7/, AICHE, 2018.

[9] H. Schinke, F. Sauerwald, Dichtemessungen XXI [1]. Über die Volumenänderung beim Schmelzen und den Schmelzprozeß bei organischen, insbesondere aromatischen Stoffen, Z. Phys. Chem., 2160 (1961) 26.

[10] M. Anderson, L. Bosio, J. Bruneaux-Poulle, R. Fourme, Toluène : structure cristalline et moléculaire de la variété stable $\alpha$ et état amorphe, J. Chim. Phys., 74 (1977) 68-73.

[11] S.K. Nayak, R. Sathishkumar, T.N.G. Row, Directing role of functional groups in selective generation of $\mathrm{C}-\mathrm{H} \cdots \pi$ interactions: In situ cryo-crystallographic studies on benzyl derivatives, CrystEngComm, 12 (2010) 3112-3118.

[12] G.F. Carruth, R. Kobayashi, Vapor pressure of normal paraffins ethane through ndecane from their triple points to about $10 \mathrm{~mm}$ mercury, J. Chem. Eng. Data, 18 (1973) 115-126.

[13] D.R. Douslin, H.M. Huffman, Low-Temperature Thermal Data on the Five Isomeric Hexanes, J. Am. Chem. Soc., 68 (1946) 1704-1708.

[14] Preston GT, Funk EW, Prausnitz JM. Solubilities of hydrocarbons and carbon dioxide in liquid methane and in liquid argon. J Phys Chem Ref Data 1971;75:2345-52.

[15] Dickinson E, Knobler CM, Scott RL. Solid/liquid phase equilibria in the mixtures methane + n-hexane and methane + n-pentane. J Chem Soc, Faraday Trans 1 1973;69:2179-87.

[16] Kurata F. GPA Research Report RR-14: Solubility of Heavier Hydrocarbons in Liquid Methane. Gas Processors Association; 1975.

[17] Kuebler GP, McKinley G. Solubility of Solid n-Butane and n-Pentane in Liquid Methane. In: Timmerhaus KD, Weitzel DH, editors. Advances in Cryogenic Engineering. Boston, MA: Springer US; 1975, p. 509-15.

[18] Morlet J. Experimental results on the density and miscibility of liquefied hydrocarbons at low temperatures. Rev Inst Fr Pet 1963;18:127-43. 
[19] Boyle GJ. Corporate Source: Shell Res. Ltd. Thornton Res. Centre P. O. Box. 1 Chester, C14-26: DECHEMA; 1973.

[20] Brew TCL. A study on the solubility of heavy hydrocarbons in liquid methane and methane containing mixtures. Chemical Engineering Department. University of Ottawa, Canada; 1977.

[21] Shim J, Kohn JP. Multiphase and Volumetric Equilibria of Methane-n-Hexane Binary System at Temperatures Between $-110^{\circ}$ and $150^{\circ}$ C. J Chem Eng Data 1962;7:3-8.

[22] Kohn JP, Luks KD, Liu PH, Tiffin DL. Three-Phase Solid-Liquid-Vapor Equilibria of the Binary Hydrocarbon Systems Methane- $n$-Octane and Methane-Cyclohexane. J Chem Eng Data 1977;22:419-21.

[23] Beck LA. Solubility, Density and Freezing Point Data for Solutions of Methane in nHexane. University of Kansas, USA; 1956.

[24] A. Neumann, Mann R. Solubility of Solid Hydrocarbons and Methanol in Liquid Methane. Kaltetechnik-Klimatisierung 1970;22:182-3.

[25] Kuebler GP, McKinley C. Solubility of Solid Benzene, Toluene, n-Hexane, and nHeptane in Liquid Methane. In: Timmerhaus KD, editor Advances in Cryogenic Engineering. Springer US; 1995, p. 320-6.

[26] Shipman LM, Kohn JP. Heterogeneous Phase and Volumetric Equilibrium in the Methane-n-Nonane System. J Chem Eng Data 1966;11:176-80.

[27] Tiffin DL, Luks KD, Kohn JP. Solubility Enhancement of Solid Hydrocarbons in Liquid Methane due to the Presence of Ethane. Adv Cryog Eng 1978;23:538-43.

[28] Chang HL, Kobayashi R. Vapor-liquid equilibria of light hydrocarbons at low temperatures and high pressures: The methane-n-heptane system. AIChE J 1966;12:1212-6.

[29] Kohn JP, Bradish WF. Multiphase and Volumetric Equilibria of the Methane-nOctane System at Temperatures between -110 and 150 C. J Chem Eng Data 1964;9:58.

[30] Brewer J, Kurata F. Freezing Points of Binary Mixtures of Methane. AIChE J 1958;4:317-8.

[31] Teller M. Experimental and Theoretical Investigation of Solid-Liquid Phase Equilibria of Binary Mixtures at Low Temperatures. TU Berlin; 1982:1-157.

[32] Beaudoin JM, Kohn JP. Multiphase and volumetric equilibria of the methane-ndecane binary system at temperatures between -36Cand 150C. J Chem Eng Data 1967;12:189-91.

[33] Luks KD, Hottovy JD, Kohn JP. Three-Phase Solid-Liquid-Vapor Equilibria in the Binary Hydrocarbon Systems Methane- $n$-Hexane and Methane-Benzene. J Chem Eng Data 1981;26:402-3.

[34] Rijkers MPWM, Malais M, Peters CJ, de Swaan Arons J. Experimental Determination of the Phase Behavior of Binary Mixtures of Methane + Benzene: Part I. Vapor + Liquid, Solid Benzene + Liquid, Solid Benzene + Vapor and Solid Benzene + Liquid + Vapor Equilibria. Fluid Phase Equilib 1992;77:327-42.

[35] GPSA. Section 16 - Hydrocarbon Recovery. GPSA Engineering Databook, 13th ed. Tulsa, Oklahoma; 2012.

[36] Neumann A, Mann R, von Szalghary WD. The Solubility of solid Benzene in liquid Hydrocarbons. Kaltetechnik-Klimatisierung 1972;24:145-9.

[37] Hughes TJ, Kandil ME, Graham BF, Marsh KN, Huang SH, May EF. Phase equilibrium measurements of (methane+benzene) and (methane+methylbenzene) at temperatures from (188 to 348)K and pressures to 13MPa. J Chem Thermodyn 2015;85:141-7. 
[38] Chang HL, Kobayashi R. Vapor-Liquid Equilibria of Methane-Toluene System at Low Temperatures and High Pressures. J Chem Eng Data 1967;12:517.

[39] Liu PH, Luks KD, Kohn JP. Three-phase solid-liquid-vapor equilibria of the systems ethane + benzene, ethane + cyclohexane and ethane + trans-decalin. J Chem Eng Data 1977;22:220-1.

[40] Kohn JP, Luks KD, Liu PH. Three-phase solid-liquid-vapor equilibriums of binary-nalkane systems (ethane-n-octane, ethane-n-decane, ethane-n-dodecane). J Chem Eng Data 1976;21:360-2.

[41] Rufford TE, Watson GCY, Saleman TL, Hofman PS, Jensen NK, May EF. Adsorption Equilibria and Kinetics of Methane + Nitrogen Mixtures on the Activated Carbon Norit RB3. Ind Eng Chem Res 2013;52:14270-81.

[42] Setzmann U, Wagner W. A New Equation of State and Tables of Thermodynamic Properties for Methane Covering the Range from the Melting Line to $625 \mathrm{~K}$ at Pressures up to 100 MPa. J Phys Chem Ref Data 1991;20:1061-155.

[43] Bücker D, Wagner W. A Reference Equation of State for the Thermodynamic Properties of Ethane for Temperatures from the Melting Line to $675 \mathrm{~K}$ and Pressures up to $900 \mathrm{MPa}$. J Phys Chem Ref Data 2006;35:205-66.

[44] Lemmon EW, Huber ML, McLinden MO. NIST Standard Reference Database 23: Reference Fluid Thermodynamic and Transport Properties-REFPROP. In: Gaithersburg M, ed. 9.1 ed.; 2013.

[45] T. Uchida, K. Yamazaki, K. Gohara. Generation of micro- and nano-bubbles in water by dissociation of gas hydrates. Korean J Chem Eng 2016;33:1749-55.

[46] Stepanova GS, Velikovskii AS. The Phase Equilibria of binary Mixtures of Methane with various Solvents. Gazovoye Delo 1969;12:10-3.

[47] Zhou Y, Wu J, Lemmon EW. Thermodynamic Properties of o-Xylene, m-Xylene, $p$ Xylene, and Ethylbenzene. J Phys Chem Ref Data 2012;41:023103--26.

[48] Vitu S, Privat R, Jaubert J-N, Mutelet F. Predicting the Phase Equilibria of $\mathrm{CO}_{2}+$ Hydrocarbon Systems with the PPR78 Model (PR EOS and kij Calculated Through a Group Contribution Method). J Supercrit Fluids 2008;45:1-26. 